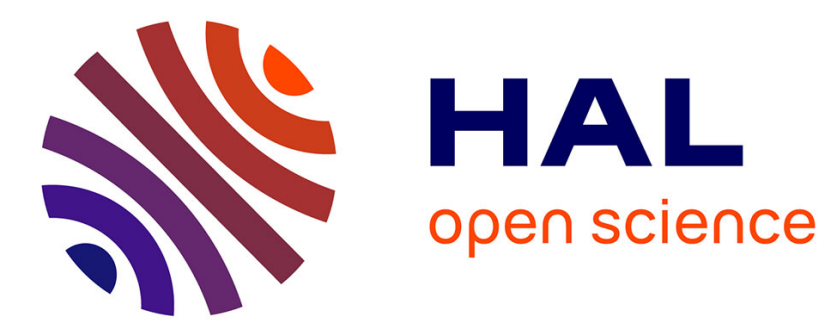

\title{
Elevation-related difference in serial reversal learning ability in a nonscatter hoarding passerine
}

Ethan Hermer, Maxime Cauchoix, Alexis Chaine, Julie Morand-Ferron

\section{To cite this version:}

Ethan Hermer, Maxime Cauchoix, Alexis Chaine, Julie Morand-Ferron. Elevation-related difference in serial reversal learning ability in a nonscatter hoarding passerine. Behavioral Ecology, 2018, 29 (4), pp.840-847. 10.1093/beheco/ary067 . hal-02347917

\section{HAL Id: hal-02347917 \\ https://cnrs.hal.science/hal-02347917}

Submitted on 20 Nov 2020

HAL is a multi-disciplinary open access archive for the deposit and dissemination of scientific research documents, whether they are published or not. The documents may come from teaching and research institutions in France or abroad, or from public or private research centers.
L'archive ouverte pluridisciplinaire HAL, est destinée au dépôt et à la diffusion de documents scientifiques de niveau recherche, publiés ou non, émanant des établissements d'enseignement et de recherche français ou étrangers, des laboratoires publics ou privés. 


\title{
Original Article
}

\section{Elevation-related difference in serial reversal learning ability in a nonscatter hoarding passerine}

\author{
Ethan Hermer, ${ }^{\mathrm{a}, \bullet}$ Maxime Cauchoix, ${ }^{\mathrm{b}, \mathrm{c}}$ Alexis S. Chaine, ${ }^{\mathrm{b}, \mathrm{c}}$ and Julie Morand-Ferron ${ }^{\mathrm{a}}$ \\ aDepartment of Biology, University of Ottawa, 30 Marie Curie, Gendron Hall 160, Ottawa, ON K1N \\ 6N5, Canada, bInstitute for Advanced Studies in Toulouse, Toulouse School of Economics, 21 allée \\ de Brienne, 31015 Toulouse, France, and 'Station d'Ecologie Théorique et Expérimentale du CNRS \\ UMR5321, Evolutionary Ecology Group, 2 route du CNRS, 09200 Moulis, France
}

Received 21 September 2017; revised 14 March 2018; editorial decision 19 March 2018; accepted 19 April 2018 ; Advance Access publication 14 May 2018.

Environments characterized by scarce and variable food supply, termed "harsh environments," have been hypothesized to favor cognitive abilities that aid an animal in finding food, remembering where it is located, or predicting its availability. Most studies of the "harsh environment" hypothesis have found that scatter hoarders from harsher environments have better spatial memory abilities, but few studies have looked at this hypothesis in nonscatter hoarders. Here, we present the first comparison of performance on a serial reversal learning task in a nonscatter hoarder from 2 elevations that differ in harshness. Serial reversal learning tasks measure a suite of cognitive abilities that are believed to allow an animal to adjust its foraging behavior to match changes in the availability of food over time. Therefore, performance on this task is predicted to increase with elevation. There was no significant difference between the high and low elevation great tits in initial reversal learning accuracy. While both high and low elevation birds were able to improve their reversal learning accuracy, they did not differ in their rate of improvement over reversals. However, we found that lower elevation birds had higher accuracy across all reversals. Contrary to the "harsh environment" hypothesis, our findings suggest that birds from the less harsh environment at low elevation performed more accurately on the reversal learning task. Overall, our results suggest that the study of the relationship between harshness and cognition in nonhoarders would benefit from taking into account other environmental factors, and trade-offs with other cognitive abilities.

Key words: altitude, cognitive ecology, intraspecific variation, operant learning, Parus major, winter resident.

Environments characterized by low food abundance and a variable food supply, termed "harsh environments," could favor cognitive abilities that help individuals cope with these challenges by enhancing their ability to find food, remember where it is located, or predict its availability (Milton 1981; Sol et al. 2005; Dukas 2009; Pravosudov and Roth 2013; Kozlovsky et al. 2017). This "harsh environment" hypothesis has been tested along latitudinal and elevation gradients, as increases in latitude and elevation can correlate to more snow cover, lower temperatures, greater seasonality, and shorter day length, which lead to greater variability in the availability of food and higher metabolic costs (Roth and Pravosudov 2009; reviewed in Boyle et al. 2016) but see Körner, 2007). Over these 2 gradients, the "harsh environment" hypothesis has been studied using scatter-hoarding birds, or birds that store food in multiple

Address correspondence to E. Hermer. E-mail: eherm041@uottawa.ca. locations, as these stored caches allow them to circumvent resource variability (Croston et al. 2015). This scatter-hoarding behavior has been shown to require spatial memory to remember and retrieve previous caches (Krebs 1990; reviewed in Sherry 1998). Empirical support for the "harsh environment" hypothesis in scatter-hoarders include positive links between elevation or latitude and the size and density of the neurological structures linked to memory (elevation: Freas et al. 2013; latitude: Freas et al. 2013; Roth et al. 2013) and behavioral measures of spatial learning and memory (reviewed in Pravosudov et al. 2015). Although a positive correlation between residual brain size, as a proxy for general cognitive ability, and resource variability has been found in a large-scale comparative study (Sayol et al. 2016), few studies have examined the "harsh environment" hypothesis in nonscatter hoarders.

Compared to the amount of knowledge that has accumulated over the past decades on the cognitive ecology of avian scatterhoarders, little is known about the cognitive solutions that may be employed by nonhoarders to survive harsh environments. However, 
models predict that if the environment contains information that can be used to acquire food efficiently or predict its availability, associative learning, or the ability to learn about the environment, would be advantageous (Mery and Burns 2010; reviewed in Dunlap and Stephens 2016). In support of this, Kotrschal and Taborsky (2010) found that a cichlid fish (Simochromis pleurospilus) that experienced a change in food abundance during development performed more accurately on an associative learning task than fish from a control treatment These findings suggest that environmental variability may activate an increase in associative learning ability, pointing to its potential usefulness in a changing environment.

In natural environments, the value of temporally and spatially variable resources can change multiple times, and thus may not only require animals to acquire learned associations, but also to track the value of multiple options and behave accordingly. The ability to collect and utilize information to flexibly adjust one's associations can be measured via reversal learning tasks (Shettleworth 2010). In a reversal learning task, an animal is required to learn to associate a stimulus with a response (e.g., associate a red well with food, and a blue well with no food) and once the animal has learned this association, the originally unrewarded stimulus is now rewarded and the rewarded stimulus becomes unrewarded (e.g., associate a blue well with food, and a red well with no food). Several reversals can also be used, such that animals have to adjust their choices repeatedly (i.e., serial reversal learning; Shettleworth 2010). Performance on reversal learning tasks is thought to measure the suite of abilities an animal would use, for example, to change its foraging behavior to match a change in food availability and therefore it can be predicted to covary with environmental harshness (Tebbich and Teschke 2014; Janmaat et al. 2016). To our knowledge, the only study that examined the relationship between "harsh environments" and reversal learning in nonscatter hoarders is Tebbich and Teschke's (2014) study on woodpecker finches (Cactospiza pallida). A single reversal was used and returned evidence that supports the "harsh environment" hypothesis, with woodpecker finches from the food-scarce, more variable desert site performing the reversal faster than those from the more stable cloud forest site.

Performance in reversal learning tasks can be measured in one or several reversals, but also as the rate of change, or improvement of performance across reversals (Bond et al. 2007; Bebus et al. 2016; Liu et al. 2016; reviewed in Izquierdo et al. 2017). The improvement of performance across reversals is believed to measure an animal's ability to learn a rule to allow them to more efficiently track resource value (e.g., win-stay/lose shift; Liu et al. 2016) or accumulate past information and better estimate a prior probability that reversals will occur (Reveiwed in Izquierdo et al. 2017). This ability could allow animals to increase the rate at which they can track recurrent changes in their environment (e.g., Strang and Sherry 2014; Liu et al. 2016; Chow et al. 2017), and could thus be advantageous in highly-changing environments. However, it has never been examined in the context of the "harsh environment" hypothesis.

Here, we present the first test of the "harsh environment" hypothesis using a serial reversal learning task. We studied great tits (Parus major) from high and low elevation sites along the Pyrénées mountain range. Great tits are nonscatter hoarding passerines that forage for patchily-distributed seeds and invertebrates during the winter (Gosler 1993). They are also able to complete associative learning, initial and serial reversal learning tasks (Amy et al. 2012; Titulaer et al. 2012; Morand-Ferron et al. 2015; Cauchoix et al. 2017). We predict great tits from higher elevations will have higher accuracy in an initial and serial reversal learning task, and will improve faster over reversals, than great tits from lower elevations.

\section{METHODS}

\section{Study sites}

Study sites were located near Moulis, France, along the north side of the Pyrénées. High (800-900 m; Galey: 42.93644" N 0.91702" E, Cap Sour: 42.93203" N 1.12322" E) and low (400-500 m; Aubert: 42.96427" N 1.10302" E, Ledar: 42.98306" N 1.11492" E, Moulis: 42.96551" N, 1.08791" E, Lab: 42.95741" N, 1.08698" E) elevation sites covered an elevation range similar to that in other studies of harsh environments (e.g., Croston et al. 2017). In the Pyrénées, this results in a temperature decrease of $2{ }^{\circ} \mathrm{C}$ (personal communication, López-Moreno and Nogués-Bravo 2005; Bruendl 2017), a shorter growing period (Ninot et al. 2017), and increased snow accumulation (López-Moreno and Nogués-Bravo 2005). Our high elevation sites were also characterized by increased weekly snow cover compared with our low elevation sites (Supplementary Material S1), which is expected to equate to lower food availability and increased variability in food availability (Boyle et al. 2016).

\section{Capture and housing}

First capture took place between 15 February 2016 and 1 March 2016 (Winter) when 21 high and 25 low elevation birds were captured. From 7 October 2016 to 22 November 2016 (Fall), an additional 8 high and 12 low elevation birds were captured (Supplementary Material S2). Great tits were captured using mist nets, and marked with a CRBPO (Centre de Recherches sur la Biologie des Populations d'Oiseaux) metal band and colored RFID band (passive integrated transponder, IB Technologies, UK). We used plumage to sex and age the birds (Svensson 1992). We placed the birds in cloth bags and transported them to outdoor aviaries in Moulis where they were housed in groups of $2-5$ per aviary $(1 \times 4 \times 3 \mathrm{~m})$, depending on how many birds were caught. Each aviary contained foliage for cover in the nontesting area, 4 roosting boxes, and 2 horizontal perches between the foliage and the testing area for perching.

\section{Operant devices}

Operant devices consisted of a single portable operant box (Morand-Ferron et al. 2015; Cauchoix et al. 2017), which was composed of a waterproof Perspex casing that contained: a motor-activated feeding tray, a printed circuit board (PCB, "Darwin board" designed by Stickman Technologies Inc., UK), and 2 transparent pecking keys lit up by white light-emitting diode (LEDs). The front panel of the operant box was freely available to any individual and displayed 2 pecking keys that each contained 2 live mealworms. The great tits were unable to consume the mealworms which instead acted as bait to elicit pecking actions. A feeding hole $1.5 \mathrm{~cm}$ under the pecking keys provided a single dried mealworm reward on the feeding tray when the correct key was pecked. A $10 \mathrm{~cm} \times$ $5 \mathrm{~cm} \times 1 \mathrm{~cm}$ PIT tag identification perch was attached outside of the box, under the feeding hole. The perch instructed the PCB to start the learning program at each individual's current position within the program (see below). For visits that led to a bird pecking a key, which we termed a trial, the PCB recorded whether the choice was correct (1) or incorrect (0). If the bird did not peck a key, no trial was recorded. 


\section{Acclimatization}

Acclimatization to the aviary occurred for the first 7-12 days of captivity. For the first 3 days, the birds were given ad libitum black oil sunflower seeds, fat balls, meal worms, and water. Additionally, a small heated $\left(25^{\circ} \mathrm{C}\right)$ room inside of the aviary building was left open and contained a second source of ad libitum food and water, as well as a constant source of light, to encourage feeding. During the acclimatization period, a wooden dummy operant box was placed at the end of the outdoor aviary, on the wooden shelf where the operant box would be during the test phase (Cauchoix et al. 2017). The dummy box was baited with seed and margarine where the pecking keys would be, and sunflower seeds alone where the reward hole would be. This was done to acclimatize the birds to the components and location of the operant device, and learn that it was a source of food. After 3 days, the adjoining room to the aviary was shut and the birds were kept only in the outdoor portion of the aviary. Dummy operant boxes were removed at the end of acclimatization.

\section{Testing}

For 2 weeks after acclimatization, the great tits were exposed to a serial spatial reversal learning task for $2 \mathrm{~h}$. Great tits were deprived of food overnight and the first hour after sunrise in the morning (08h00), and for $1 \mathrm{~h}$ in the afternoon (14h00). Operant boxes were in the cages for a total of $2 \mathrm{~h}$ after each deprivation period, where great tits could engage freely in any number of trials by visiting the device. In total, 28 sessions occurred over 14 days for each group. Reward wheels were checked and replenished halfway through each session when depleted. After the $2 \mathrm{~h}$ testing intervals, great tits received ad libitum food and water, and the operant boxes were shut off and covered.

The first landing an individual great tit made that resulted in a peck to a pecking key, i.e., the first trial, started its learning program (Cauchoix et al. 2017). After this trial, the bird received a reward and the motor training stage started. In this stage, an individual great tit was required to peck the same key it had previously pecked to receive a reward. If the opposite key was pecked, both LEDs would shut off for $500 \mathrm{~ms}$ and turn back on. Once an individual obtained 9 correct trials in total during the motor training stage, it proceeded to the first reversal learning stage. During the first reversal learning stage, individuals had to inhibit pecking the past correct key from the motor training stage, and instead peck the other key. Incorrect pecks led to the LEDs turning off, and the operant box would become unresponsive to that individual great tit for a set amount of time. Due to technical issues, a slightly different program was used in each season; in the winter, the punishment period lasted $15 \mathrm{~s}$ or until another bird visited the device, while for fall birds it lasted $5 \mathrm{~s}$ regardless of whether another bird visited the device or not (included as a covariate in analyses as "season"). The first reversal stage was completed when an individual pecked the correct pecking key in 9 out of 10 successive trials. The second reversal stage would then commence and this individual would have to peck the opposing pecking key from the first reversal stage and again peck the correct key in 9 of 10 successive trials before moving to the next reversal. This alternation between right-key and left-key rewarded pecks would continue with each successive stage up to a maximum of 18 serial reversals. This progression of stages was the same for each bird and progress was maintained across each 2-week reversal learning period.

\section{Statistical analysis}

To discern whether there was a difference in initial motivation, acclimatization or motor proficiency with the task between high and low elevation birds, we tested for differences in the proportion of birds using the device (i.e., returning a first peck), the proportion of birds completing the motor training phase, the first reversal, and the final reversal (18th reversal) with Pearson's chi-squared tests with Yates' continuity correction. We also compared the mean session number (out of 28 sessions) when the birds registered a first peck and completed the motor training stage between elevations using all birds that made it to each of these stages using a nonpaired Wilcoxonsigned rank test, as these data did not meet the assumption of normality. Due to technical difficulties, one high elevation bird did not have a time for first peck and was excluded from the comparison of the mean session number when the birds registered a first peck

To determine whether there was a difference in the pace at which trials were taken by birds from high and low elevation, which could have impacted their ability to remember learned associations, we compared their intertrial interval (ITI) durations during reversal learning. We could model only $80.7 \%$ (88/109) of the fall bird's reversals due to technical difficulties that returned missing timing information for some ITIs. We used a linear mixed-model with Gaussian distribution (LMM). The dependent variable, ITI (number of seconds from the last reversal trial), was log-transformed to better meet the assumptions of the model. The independent variable was high or low elevation and bird ID was included as a random intercept. We compared this model against the null model using a likelihood ratio test.

We examined the differences in both initial and serial reversal learning accuracy between elevations using generalized linear mixed models (GLMM) with a binary response (1: trial correct, 0 : trial incorrect). We included fixed effects of elevation (High, Low), sex (Male, Female), age (Juvenile, Adult), trial number, and group size. We also included a fixed effect of season (Fall, Winter), to control for differences in the programmed delay after an incorrect peck and potential seasonal effects. Bird ID and capture site were included as random intercepts (Schielzeth and Forstmeier 2008).

In the initial reversal model, the random intercept of site returned a zero-variance estimate and we were thus unable to control for a site effect with this approach. To check for a site effect, we used 2 separate high and low elevation models that contained their respective sites as a fixed effect. The high and low elevation models would not converge with group size included and so it was dropped for these analyses. The effect of site was not significant in either high or low elevation models (see Supplementary Materials S3, S4, S5, S6) and it was thus excluded from further analyses.

The serial reversal model utilized the same variables as those used for initial reversal learning, with the addition of a reversal number $\times$ elevation interaction to test for elevation-related differences in reversal learning improvement, and a random slope of ID $\times$ reversal number to account for individual variation in improvement in accuracy over reversals (Schielzeth and Forstmeier 2008). To check for a site effect in the serial reversal learning models we compared a model with and without the random effect of site using a likelihood ratio test; as it was not significant $\left(\chi^{2}=24073, P=1\right)$, we excluded it from further analysis.

LMMs and GLMMs were fit using the statistical package lme4 (Bates et al. 2015) in $R$ (version 3.4.4, R Core Team, 2018). We used Akaike's Information Criterion adjusted for small sample size (AICc) for model selection (R package MuMIn; Bartoń 2018). 
We performed model averaging using models within $<\Delta 2$ AICc of the top model (Grueber et al. 2011). All continuous predictor variables were standardized by grand mean centering and dividing by 1 standard deviation. Means are presented with their standard errors. Three low elevation birds from the fall experiments were exposed to a similar task during pretrials in the previous winter; 2 did not contact the device and 1 only passed the motor training stage. We reran all analyses (Participation, Initial Contact and Motor Training, ITI, Initial Reversal and Serial Reversal) while excluding these data points; our conclusions were unchanged and therefore we report results from the full dataset below.

\section{Ethical note}

This work was conducted under animal care permits to from the French bird ringing office (CRBPO; $\left.{ }^{\circ} 13619\right)$ and animal experimentation review from the state of Ariège (Préfecture de l'Ariège, Protection des Populations, $\left.\mathrm{n}^{\circ} \mathrm{A} 09-4\right)$ and the Région MidiPyrenées (DIREN, n²012-07). Birds were housed in the Moulis experimental aviaries (Préfecture de l'Ariège, institutional permit nSA-12-MC-054) under animal captivity permits (Préfecture de l'Ariège, Certificat de Capacite, $\left.n^{\circ} 09-321\right)$. One great tit from winter capture died during acclimatization.

\section{RESULTS}

\section{Participation}

All birds pecked the device at least once (High: 28/28; Low: 24/24). We found no significant difference between high and low elevation birds in the proportion of birds that passed the motor training phase (High: 24/28, 22/24. Contingency table: $\chi^{2}=0.055$, df $=1$, $P=0.815$ ), passed at least one reversal (High: 18/28, 13/24. Contingency table: $\chi^{2}=0.210, \mathrm{df}=1, P=0.647$ ), nor in the proportion of birds that completed the final reversal (High: 11/28, Low: 10/24. Contingency table: $\chi^{2}<0.001$, df $=1, P=1$ ).

\section{Initial contact and motor training}

There was no significant difference between elevations in the number of learning sessions before they first pecked a key (High: $4.00 \pm 4.17$; Low: $2.21 \pm 2.02$; Wilcoxon rank sum test, high vs. low: $\mathrm{W}=416.5, P=0.066, \mathcal{N}=51$ ), or before they passed the motor training phase (High: $7.48 \pm 6.10$; Low: $7.23 \pm 6.89$; Wilcoxon rank sum test, high vs. low: $\mathrm{W}=261, P=0.864, \mathcal{N}=46$ ).

\section{Initial reversal learning}

Elevation, sex, age, capture season, and group size had no significant effect on reversal learning accuracy in the first reversal. Trial number had a significant positive effect on accuracy which indicates that the birds improved their accuracy within the first reversal (Tables 1 and 2).

\section{Serial reversal learning}

The reversal number $\times$ elevation interaction was not a significant predictor of accuracy (GLMM: $z=0.423, P=0.672$ ), suggesting that the rate of improvement over successive reversals did not differ between high and low elevation birds (see Supplementary Materials S7 and S8). This interaction was excluded from further analyses. Across all reversals, low elevation birds performed significantly more accurately than high elevation birds (Figure 1). There was no significant difference between capture season, sex, age, and group size in reversal learning accuracy. Both trial and reversal number
Table 1

Models within $<\Delta 2$ AICc of the top model for initial reversal learning accuracy (1: correct 0 : incorrect), their coefficients, degrees of freedom, AICc, $\Delta \mathrm{i}$, and Akaike weights

\begin{tabular}{lllll} 
Candidate Models & df & AICc & $\Delta \mathrm{i}$ & $\omega \mathrm{i}$ \\
\hline Sex+Trial+(1|ID) & 4 & 1919.47 & 0.00 & 0.14 \\
Trial+(1|ID) & 3 & 1919.56 & 0.10 & 0.14 \\
Elevation+Sex+Trial+(1|ID) & 5 & 1919.65 & 0.18 & 0.13 \\
Group Size+Trial+(1|ID) & 4 & 1920.78 & 1.31 & 0.07 \\
Season+Trial+(1|ID) & 4 & 1920.85 & 1.39 & 0.07 \\
Season+Sex+Trial+(1|ID) & 5 & 1920.91 & 1.44 & 0.07 \\
Elevation+Season+Sex+Trial+(1|ID) & 6 & 1920.93 & 1.46 & 0.07 \\
Age+Sex+Trial+(1|ID) & 5 & 1921.10 & 1.63 & 0.06 \\
Season+Group Size+Trial+(1|ID) & 5 & 1921.22 & 1.75 & 0.06 \\
Elevation+Group & 6 & 1921.23 & 1.76 & 0.06 \\
Size+Sex+Trial+(1|ID) & & & & \\
Elevation+Trial+(1|ID) & 4 & 1921.24 & 1.77 & 0.06 \\
Group Size+Sex+Trial+(1|ID) & 5 & 1921.26 & 1.79 & 0.06 \\
& & & & \\
\hline
\end{tabular}

had significant positive effects on accuracy, which indicates that the birds improved their performance within reversals (trials) and across successive reversals (Tables 3 and 4). Elevation was not a significant predictor of intertrial interval duration (GLMM: $\chi^{2}=0.504$, $P=0.478)$.

\section{DISCUSSION}

The study of the relationship between cognitive abilities and environmental harshness is still a novel subject, and has only been examined in a restricted number of ecological scenarios and species. Here, we performed the first serial reversal learning comparison between individuals from different elevations. We found that there was no difference in the performance of great tits from high and low elevation during the first reversal but when examining performance across all reversals, lower elevation birds were significantly more accurate than high elevation birds. There were no elevation-related differences in the rate of improvement across reversals, although birds from both elevations significantly increased their choice accuracy over successive reversals.

The "harsh environment" hypothesis predicts that reversal learning ability should increase with harshness (Tebbich and Teschke 2014). In contrast we report: 1) no significant difference in initial reversal accuracy, and 2) higher accuracy over all reversals in birds from low, less harsh environments than in birds from high elevations. Tebbich and Teschke (2014) found support for the "harsh environment" hypothesis with woodpecker finches: individuals from a harsher desert habitat completed a reversal learning task faster than those from a less harsh cloud forest habitat. The opposing results of our study and Tebbich and Teschke's (2014) are surprising, given that our study species, the great tit, and the woodpecker finches in Tebbich and Teschke's (2014) study, are both non-migratory and non-scatter hoarders (Gosler 1993; Tebbich et al. 2002). However, the 2 species differ in other aspects; for instance, woodpecker finches came from populations that differ in tool use, with finches from the harsher environment utilizing tools more frequently than those from the less harsh environment, which may select for greater reversal learning ability in the population from the harsher environment (Tebbich et al. 2002, but see Teschke et al. 2011).

Our results across all reversals concur with those of Croston et al. (2017), who utilized a scatter-hoarding species and found that performance on a single spatial reversal of mountain chickadees 
Table 2

Summary of results of model-averaged coefficients for initial reversal learning accuracy (1: correct 0 : incorrect)

\begin{tabular}{|c|c|c|c|c|c|}
\hline Parameter & Estimate & Unconditional SE & Confidence interval & Relative importance & $P$-value \\
\hline Intercept & 0.256 & 0.319 & $(-0.370,0.882)$ & & 0.423 \\
\hline Sex (Female) & 0.360 & 0.421 & $(-0.155,1.362)$ & 0.60 & 0.392 \\
\hline Trial & 3.334 & 0.333 & $(2.681,3.986)$ & 1.00 & $<0.001$ \\
\hline Elevation (Low) & 0.149 & 0.312 & $(-0.310,1.241)$ & 0.32 & 0.633 \\
\hline Group Size & -0.136 & 0.410 & $(-1.852,0.780)$ & 0.25 & 0.741 \\
\hline Season (Fall) & -0.089 & 0.237 & $(-1.033,0.376)$ & 0.27 & 0.708 \\
\hline Age (Adult) & 0.193 & 0.144 & $(-0.660,1.266)$ & 0.06 & 0.894 \\
\hline
\end{tabular}

The estimates are from the full average of 12 models $<\Delta 2$ AIC of the top model. Full model: Correct/Incorrect $=$ Group Size + Sex + Age + Season + Elevation + Trial + (1ID).

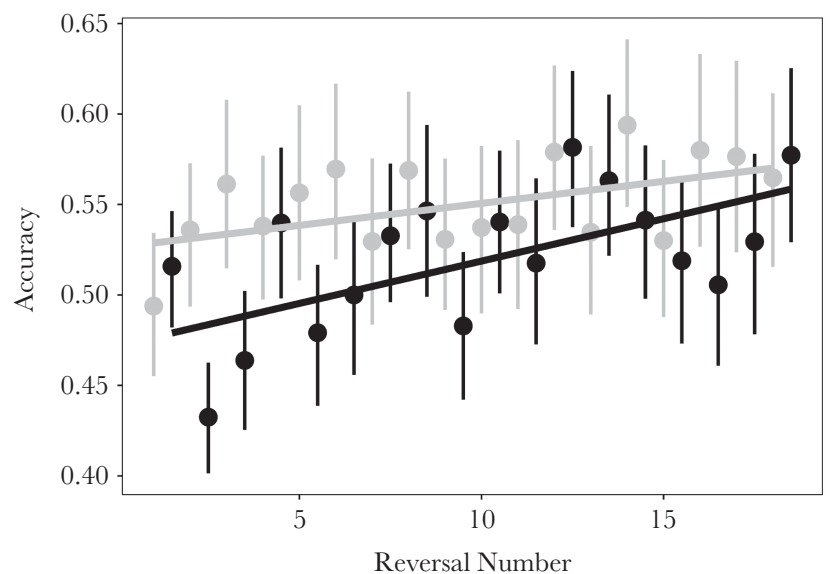

Figure 1

Mean accuracy of the individual bird's raw accuracy data, with 95\% confidence intervals calculated using a non-parametric bootstrap, as a function of reversal number, for high and low elevations. The trend line is estimated from a general linear model of the relationship of choice accuracy across reversals for high and low elevations. Black points are high elevation, gray points are low elevation.

(Poecile gambeli) was inversely related to elevation. The authors suggested that this difference was due to the high elevation chickadees' stronger spatial memory causing proactive interference, i.e. their stronger memories make it difficult to forget past associations and remember new ones (Gonzalez et al. 1967; Croston et al. 2017). This interpretation may also apply to our study population; if food is less abundant at high elevation (reviewed in Boyle et al. 2016), high elevation great tits may rely more strongly on spatial memory to remember patches of food as they find them, so they can efficiently return when their current patch has been depleted (reviewed in Milton 1981; Janmaat et al. 2016). Consequently, they may suffer from greater proactive interference than low elevation great tits, and perform worse at the serial spatial reversal learning task, which required frequently switching spatial associations. It is not currently known whether great tits from the harsh, high elevation sites exhibit increased spatial memory compared with their low elevation counterparts. If this is the case, then high elevation great tits may rely on durable, rather than flexible, spatial memory, to survive in a harsh environment.

Another possible explanation for our results is that environmental harshness itself may not be the main driver of reversal learning ability in our system. Instead, our results may be due to other ecological differences, such as population density or resource breadth.
Population density seems to decrease as elevation increases in our system (personal communication) and it has been hypothesized (Dunbar 1998) and shown that living in complex social structures can be associated with increased serial reversal learning performance (Bond et al. 2007; Ashton et al. 2018). Larger flocks may require increased reversal learning ability to compete and interact with more conspecifics at low elevations. Furthermore, if there is a higher density of individuals foraging together at a single patch, food patches may deplete faster than those at higher elevations where only a few birds utilize them. If patches are depleted faster at low elevations, then low elevation birds may require greater reversal learning ability than high elevation birds to more efficiently switch between rapidly depleting resources. Moreover, if lower elevations have a greater diversity of available types of food (i.e., seed from various tree species; (Pausas and Austin 2001; reviewed in Pausas et al. 2003) this may require greater reversal learning ability to maximize consumption of the best available food. In contrast, high elevation birds may only have the opportunity to consume a few food types and rarely utilize reversal learning to switch between optimal food types.

Although we found a difference in overall reversal learning accuracy between high and low elevation great tits, these differences could potentially be due to differences in these population's reactions to the testing environment (e.g., Calandreau et al. 2011; Thai et al. 2013). For instance, high and low elevation birds may have differed in their motivation to start or continue through the task, which could affect reversal learning performance (e.g., Liu et al. 2016). Both high and low altitude birds had at least 7 days to acclimate to the testing environment, but to ensure that the effect of elevation on reversal learning performance was not due to differences in acclimatization to the test environment and/or motivation, we compared participation between the high and low elevation great tits. All birds participated in the task. There was no significant difference between elevations in the proportion of birds that completed the motor training stage, at least one reversal, or completed all reversals. Drop-out rates are similar to those found in free-ranging great tits performing the same task (Cauchoix et al. 2017). Additionally, there was no significant difference in the session number the birds started the task nor when they successfully passed the motor training phase. Therefore, we believe the differences in reversal learning between low and high elevation birds were not due to differences in motivation and/or acclimatization. Finally, high and low elevation birds could have worked on the task at different rates; for example, high elevation birds could have waited less time between trials and thus retained a stronger memory of the previous trial, increasing the accuracy of their decisions 
Table 3

Models within $<\Delta 2$ AICc of the top model for serial reversal learning accuracy (1: correct 0 : incorrect), their coefficients, degrees of freedom, AICc, $\Delta \mathbf{i}$, and Akaike weights

Candidate models df $\quad$ AICc $\quad \Delta \mathrm{i}$

$\omega \mathrm{i}$

Elevation+Season+Reversal Number+Trial+(1+Reversal Number |ID $)$

Elevation+Reversal Number+Trial+(1+Reversal Number |ID)

Elevation+Season+Group Size+Reversal Number+Trial+ $(1+$ Reversal Number |ID $)$

Elevation+Group Size+Reversal Number+Trial+ $(1+$ Reversal Number $\mid$ ID $)$

Elevation+Season+Sex+Reversal Number+Trial+(1+Reversal Number $\mid$ ID $)$

Age+Elevation+Season+Reversal Number+Trial+(1+Reversal Number $\mid$ ID $)$

$\begin{array}{llll}8 & 24,091.56 & 0.00 & 0.26 \\ 7 & 24,091.75 & 0.18 & 0.24 \\ 9 & 24,091.99 & 0.42 & 0.21 \\ 8 & 24,093.34 & 1.77 & 0.11 \\ 9 & 24,093.54 & 1.98 & 0.10 \\ 9 & 24,093.55 & 1.98 & 0.10\end{array}$

Table 4

Summary of results of model-averaged coefficients for serial reversal learning: effects of each parameter on the accuracy (1: correct, 0: incorrect) of choice during reversals 1-18

\begin{tabular}{|c|c|c|c|c|c|}
\hline Parameter & Estimate & Unconditional SE & Confidence interval & Relative importance & $P$-value \\
\hline Intercept & 0.111 & 0.066 & $(-0.018,0.239)$ & & 0.093 \\
\hline Elevation (Low) & 0.242 & 0.084 & $(0.077,0.408)$ & 1.00 & 0.004 \\
\hline Season (Fall) & -0.090 & 0.094 & $(-0.301,0.027)$ & 0.66 & 0.337 \\
\hline Reversal Number & 0.525 & 0.148 & $(0.235,0.814)$ & 1.00 & $<0.001$ \\
\hline Trial & 3.398 & 0.106 & $(3.190,3.606)$ & 1.00 & $<0.001$ \\
\hline Group Size & -0.059 & 0.136 & $(-0.552,0.175)$ & 0.32 & 0.662 \\
\hline Sex (Female) & -0.001 & 0.027 & $(-0.183,0.157)$ & 0.10 & 0.963 \\
\hline Age (Adult) & 0.001 & 0.033 & $(-0.192,0.221)$ & 0.10 & 0.966 \\
\hline
\end{tabular}

The estimates are from the full average of 6 models $<\Delta 2$ AIC of the top model. Full model: Correct/Incorrect $=$ Group Size + Age + Sex + Season + Trial + Elevation + Reversal Number + (1+Reversal Number $\mid$ ID).

(e.g., Rayburn-Reeves et al. 2013). However, this explanation seems unlikely as ITI was also not significantly different between elevations.

Birds from both elevations were able to increase their serial reversal learning accuracy across reversals, and did not differ in their rate of performance improvement. The ability to improve performance over successive reversals is conserved across taxa (e.g., Passeriformes: Bond et al. 2007; Squamata: Gaalema 2011; Hymenoptera: Strang and Sherry 2014; Anura: Liu et al. 2016; Rodentia: Chow et al. 2017; Primates: Hassett and Hampton 2017), and has been reported before in free-ranging and captive great tits (Cauchoix et al. 2017). To further our understanding of how great tits were able to increase their serial reversal learning accuracy, future studies could add modifications to the serial reversal learning task. The addition of a second reversal test using a different type of cue (e.g., colour and spatial: Bond et al. 2007) or different subsets of cues (e.g., multiple combinations of colours: Parker et al. 2012) could provide evidence of rule learning. The addition of a third, middle option to our test would allow us to determine whether proactive interference errors (i.e., peck the previously rewarded buttons) or exploration errors (i.e., peck the button not previously rewarded to collect more data) occurred (reviewed in Izquierdo et al. 2017).

Overall, our results suggest that lower elevation great tits perform more accurately on a serial spatial reversal learning task than higher elevation birds. This difference was detected only over multiple reversals, possibly because of increased statistical power compared with an analysis on a single reversal, pointing to the usefulness of serial reversal learning as a paradigm to examine differences in reversal learning performance. More generally, our results suggest that the relationship between food variability, food scarcity, and cognition may not be consistent across all species or all harshness gradients. Furthermore, trade-offs between useful cognitive abilities such as spatial memory (Croston et al. 2017) and alternative factors, such as social complexity (Bond et al. 2007), may also drive variation in reversal learning ability. On their own, these results do not allow rejection of the "harsh environment" hypothesis, but suggests that we need a clearer definition of what constitutes a "harsh" environment. Future studies would benefit from measuring the spatial and temporal variation in ecological variables to properly define the "harshness" of a system, so as to build a greater understanding of the links between cognition and the environment (Kozlovsky et al. 2017).

\section{SUPPLEMENTARY MATERIAL}

Supplementary data are available at Behavioral Ecology online.

\section{FUNDING}

This work was supported by Human Frontiers Science Program (HFSP) (RGP 0006/2015 "WildCog" to A.S.C. and J.M.F.), and Natural Sciences and Engineering Research Council of Canada (NSERC) Discovery grant (435596-2013 to J.M.F.). This work is part of the Laboratoire d'Excellence (LABEX) entitled IAST that provided support for M.C. and TULIP (ANR10-LABX-41) for A.S.C.

The authors thank Edoxie Allier, Celia Sineau, Amandine Basset, Gwennan Giraud, Justine Le Vaillant, David Vallecillo, Armand Ziller, Maelle Freteault, and Josh Lynton-Jenkins for help with capture, animal husbandry, and for their constructive comments, Cecile Mahnich for help with data collection, Alice Thiney for help with capture, Julian Evans, Marie-Bé Leduc, and Ferran Sayol for help with the MODIS data collection, and 2 anonymous reviewers for providing helpful comments on ways to improve this manuscript.

Data accessibility: Analysis reported in this article can be reproduced using the data provided by Hermer et al (2018).

Handling editor: John Skelhorn 


\section{REFERENCES}

Amy M, van Oers K, Naguib M. 2012. Worms under cover: relationships between performance in learning tasks and personality in great tits (Parus major). Anim Cogn. 15:763-770.

Ashton BJ, Ridley AR, Edwards EK, Thornton A. 2018. Cognitive performance is linked to group size and affects fitness in Australian magpies. Nature. 554:364-367.

Bartón K. 2018. Multi-model inference. R package version 1.40.4. Available from: https://cran.r-project.org/web/packages/MuMIn/index.html.

Bates D, Maechler M, Bolker B, Walker S. 2015. Fitting linear mixed-effects models using lme4. J Stat Softw. 67:1-48.

Bebus SE, Small TW, Jones BC, Elderbrock EK, Schoech SJ. 2016. Associative learning is inversely related to reversal learning and varies with nestling corticosterone exposure. Anim Behav. 111:251-260.

Bond AB, Kamil AC, Balda RP. 2007. Serial reversal learning and the evolution of behavioral flexibility in three species of North American corvids (Gymnorhinus cyanocephalus, Nucifraga columbiana, Aphelocoma californica). J Comp Psychol. 121:372-379.

Boyle AW, Sandercock BK, Martin K. 2016. Patterns and drivers of intraspecific variation in avian life history along elevational gradients: a metaanalysis. Biol Rev. 91:469-482.

Bruendl AC. 2017. Parental investment across an altitudinal gradient in blue tits (Cyanistes caeruleus). PhD thesis, University of Exeter, Exeter, England.

Calandreau L, Bertin A, Boissy A, Arnould C, Constantin P, Desmedt A, Guémené D, Nowak R, Leterrier C. 2011. Effect of one week of stress on emotional reactivity and learning and memory performances in Japanese quail. Behav Brain Res. 217:104-110.

Cauchoix M, Hermer E, Chaine AS, Morand-Ferron J. 2017. Cognition in the field: comparison of reversal learning performance in captive and wild passerines. Sci Rep. 7:12945.

Chow PKY, Leaver LA, Wang M, Lea SEG. 2017. Touch screen assays of behavioural flexibility and error characteristics in Eastern grey squirrels (Sciurus carolinensis). Anim Cogn. 20:459-471.

Croston R, Branch CL, Kozlovsky DY, Roth TC $2^{\text {nd }}$, LaDage LD, Freas CA, Pravosudov VV. 2015. Potential mechanisms driving population variation in spatial memory and the hippocampus in food-caching chickadees. Integr Comp Biol. 55:354-371.

Croston R, Branch CL, Pitera AM, Kozlovsky DY, Bridge ES, Parchman TL, Pravosudov VV. 2017. Predictably harsh environment is associated with reduced cognitive flexibility in wild food-caching mountain chickadees. Anim Behav. 123:139-149.

Dukas R. 2009. Learning mechanisms, ecology, and evolution. In: Dukas R, Ratcliff JM, editors. Cognitive ecology II. Chicago: University of Chicago Press. p. 7-26.

Dunbar RIM. 1998. The social brain hypothesis. Evol Anthropol. 9:178-190.

Dunlap AS, Stephens DW. 2016. Reliability, uncertainty, and costs in the evolution of animal learning. Curr Opin Behav Sci. 12:73-79.

Freas CA, Bingman K, Ladage LD, Pravosudov VV. 2013. Untangling elevation-related differences in the hippocampus in food-caching mountain chickadees: the effect of a uniform captive environment. Brain Behav Evol. 82:199-209.

Freas CA, Roth TC $2^{\text {nd }}$, LaDage LD, Pravosudov VV. 2013. Hippocampal neuron soma size is associated with population differences in winter climate severity in food-caching chickadees. Funct Ecol. 27:1341-1349.

Gaalema DE. 2011. Visual discrimination and reversal learning in rough-necked monitor lizards (Varanus rudicollis). J Comp Psychol. 125:246-249.

Gonzalez RC, Behrend ER, Bitterman ME. 1967. Reversal learning and forgetting in bird and fish. Science. 158:519-521.

Gosler AG. 1993. The great tit. London: Hamlyn.

Grueber CE, Nakagawa S, Laws RJ, Jamieson IG. 2011. Multimodel inference in ecology and evolution: challenges and solutions. J Evol Biol. 24:699-711

Hassett TC, Hampton RR. 2017. Change in the relative contributions of habit and working memory facilitates serial reversal learning expertise in rhesus monkeys. Anim Cogn. 20:485-497.

Hermer E, Cauchoix M, Chaine AS, Morand-Ferron J. 2018. Data from: elevation related difference in serial reversal learning ability in a nonscatter hoarding passerine. Dryad Digital Repository. http://dx.doi. org/10.5061/drvad.20bv259

Izquierdo A, Brigman JL, Radke AK, Rudebeck PH, Holmes A. 2017. The neural basis of reversal learning: an updated perspective. Neuroscience. $345: 12-26$.
Janmaat KR, Boesch C, Byrne R, Chapman CA, Goné Bi ZB, Head JS, Robbins MM, Wrangham RW, Polansky L. 2016. Spatio-temporal complexity of chimpanzee food: how cognitive adaptations can counteract the ephemeral nature of ripe fruit. Am J Primatol. 78:626-645.

Körner C. 2007. The use of 'altitude' in ecological research. Trends Ecol Evol. 22:569-574.

Kotrschal A, Taborsky B. 2010. Environmental change enhances cognitive abilities in fish. PLoS Biol. 8:e1000351.

Kozlovsky DY, Weissgerber EA, Pravosudov VV. 2017. What makes specialized food-caching mountain chickadees successful city slickers? Proc R Soc B. 284:20162613

Krebs JR. 1990. Food-storing birds: adaptive specialization in brain and behaviour? Philos Trans R Soc Lond B Biol Sci. 329:153-160.

Liu Y, Day LB, Summers K, Burmeister SS. 2016. Learning to learn: advanced behavioural flexibility in a poison frog. Anim Behav. 111:167-172.

López-Moreno JI, Nogués-Bravo D. 2005. A generalized additive model for the spatial distribution of snowpack in the Spanish Pyrenees. Hydrol Process. 19:3167-3176.

Mery F, Burns JG. 2010. Behavioural plasticity: an interaction between evolution and experience. Evol Ecol. 24:571-583.

Milton K. 1981. Distribution patterns of tropical plant foods as an evolutionary stimulus to primate mental development. Am Anthropol. 83:534-548.

Morand-Ferron J, Hamblin S, Cole EF, Aplin LM, Quinn JL. 2015. Taking the operant paradigm into the field: associative learning in wild great tits. PLoS One. 10:e0133821.

Ninot JM, Carrillo E, Ferré A. 2017. Chapter 8 the pyrenees. In: Loidi J, editor. The vegetation of the iberian peninsula. Vol. 12. Cham, Switzerland: Springer International Publishing. p. 323-366.

Parker MO, Gaviria J, Haigh A, Millington ME, Brown VJ, Combe FJ, Brennan CH. 2012. Discrimination reversal and attentional sets in zebrafish (Danio rerio). Behav Brain Res. 232:264-268.

Pausas JG, Austin MP. 2001. Patterns of plant species richness in relation to different environments : an appraisal. J Veg Sci. 12:153-166.

Pausas JG, Carreras J, Ferré A, Font X. 2003. Coarse-scale plant species richness in relation to environmental heterogeneity. J Veg Sci. 14:661-668.

Pravosudov VV, Roth $2^{\text {nd }}$ TC. 2013. Cognitive ecology of food hoarding: the evolution of spatial memory and the hippocampus. Annu Rev Ecol Evol Syst. 44:173-193.

Pravosudov VV, Roth TG, LaDage LD, Freas CA. 2015. Environmental influences on spatial memory and the hippocampus in food-caching chickadees. Comp Cogn Behav Rev. 10:25-43.

R Core Team. 2018. R: A language and environment for statistical computing. Vienna, Austria: R Foundation for Statistical Computing.

Rayburn-Reeves RM, Laude JR, Zentall TR. 2013. Pigeons show nearoptimal win-stay/lose-shift performance on a simultaneous-discrimination, midsession reversal task with short intertrial intervals. Behav Processes. 92:65-70.

Roth TC $2^{\text {nd }}$, Chevalier DM, LaDage LD, Pravosudov VV. 2013. Variation in hippocampal glial cell numbers in food-caching birds from different climates. Dev Neurobiol. 73:480-485.

Roth TC, Pravosudov VV. 2009. Hippocampal volumes and neuron numbers increase along a gradient of environmental harshness: a large-scale comparison. Proc Biol Sci. 276:401-405.

Sayol F, Maspons J, Lapiedra O, Iwaniuk AN, Székely T, Sol D. 2016 Environmental variation and the evolution of large brains in birds. Nat Commun. 7:13971.

Schielzeth H, Forstmeier W. 2008. Conclusions beyond support: overconfident estimates in mixed models. Behav Ecol. 20:416-420.

Sherry DF. 1998. The ecology and neurobiology of spatial memory. In: Dukas R, editor. Cognitive ecology. 1st ed. Chicago: University of Chicago Press. p. 261-296.

Shettleworth SJ. 2010. Discrimination, classification and concepts. In: Shettleworth SJ, editor. Cognition, evolution and behaviour. 2nd ed. New York: Oxford University Press. p. 186-188.

Sol D, Lefebvre L, Rodríguez-Teijeiro JD. 2005. Brain size, innovative propensity and migratory behaviour in temperate Palaearctic birds. Proc Biol Sci. 272:1433-1441.

Strang CG, Sherry DF. 2014. Serial reversal learning in bumblebees (Bombus impatiens). Anim Cogn. 17:723-734.

Svensson L. 1992. Identification guide to european passerines. 4th ed. Stockholm, Sweden: British Trust for Ornithology.

Tebbich S, Taborsky M, Fessl B, Dvorak M. 2002. The ecology of tool-use in the woodpecker finch (Cactospiza pallida). Ecol Lett. 5:656-664. 
Tebbich S, Teschke I. 2014. Coping with uncertainty: woodpecker finches (Cactospiza pallida) from an unpredictable habitat are more flexible than birds from a stable habitat. PLoS One. 9:e91718.

Teschke I, Cartmill EA, Stankewitz S, Tebbich S. 2011. Sometimes tool use is not the key: no evidence for cognitive adaptive specializations in toolusing woodpecker finches. Anim Behav. 82:945-956.
Thai CA, Zhang Y, Howland JG. 2013. Effects of acute restraint stress on set-shifting and reversal learning in male rats. Cogn Affect Behav Neurosci. 13:164-173.

Titulaer M, van Oers K, Naguib M. 2012. Personality affects learning performance in difficult tasks in a sex-dependent way. Anim Behav. 83:723-730. 